\title{
ANÁLISE FLORÍSTICA E ESTRUTURAL DO COMPONENTE ARBÓREO DE UM FRAGMENTO DE FLORESTA OMBRÓFILA MISTA EM CLEVELÂNDIA, SUDOESTE DO PARANÁ
}

\author{
Floristic and structural analysis of the tree component of a Subtropical \\ Ombrophilous Forest fragment, in Clevelandia, southwestern region of Parana State
}

\author{
Álvaro Felipe Valério ${ }^{a}$, Luciano Farinha Watzlawick ${ }^{\mathrm{b}}$, Rafaelo Balbinot ${ }^{\mathrm{c}}$ \\ a Engenheiro Florestal, Mestrando em Manejo Florestal - UNICENTRO. Bolsista Capes. Clevelândia, PR - Brasil, e- \\ mail:alvarofvalerio@yahoo.com.br

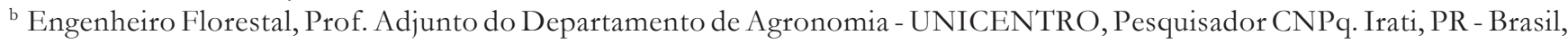 \\ e-mail: luciano.watzlawick@pq.cnpq.br \\ c Engenheiro Florestal, Doutorando em Conservação da Natureza - UFPR. Curitiba, PR - Brasil, e-mail: rbalbinot@yahoo.com.br
}

\section{Resumo}

No estado do Paraná, as Florestas com Araucária se encontram alteradas e fragmentadas pela ação antrópica. O presente estudo teve como objetivo conhecer, analisar e descrever a composição florística e a estrutura do componente arbóreo de um fragmento de Floresta Ombrófila Mista, no município de Clevelândia, localizado na região Sudoeste do Estado do Paraná. Para isto foram instaladas, aleatoriamente, 20 unidades amostrais de $400 \mathrm{~m} 2$, onde foram medidas e identificadas todas as árvores com DAP $\geq 20 \mathrm{~cm}$. Foi constatada a presença de 26 espécies pertencentes a 23 gêneros, distribuídos em 18 famílias botânicas. As famílias com maior número de espécies foram: Sapindaceae (4); Lauraceae (3); Myrtaceae, Euphorbiaceae e Aquifoliaceae (2). Foi observada uma espécie de cada uma das demais famílias.

Palavras-chave: Caracterização fitossociológica; Ocorrência de espécies; Floresta com Araucária.

\section{Abstract}

The Subtropical Ombrophilous Forest in Parana state have been altered and fragmented by anthropic action. The current study has as objective to know, analyze and describe the floristic and the tree component structure of a Subtropical Ombrophilous Forest fragment, in the municipality of Clevelandia, Parana state southwestern region. For this, 20 sample unities 
with $400 \mathrm{~m} 2$ each were placed randomly, in which all trees with $\mathrm{DBH} \geq 20 \mathrm{~cm}$ were measured and identified. Twenty six species were identified, of 23 genera and distributed in 18 botanicals families. The families with higher number of species were: Sapindaceae (4); Lauraceae (3); Myrtaceae, Euphorbiaceae and Aquifoliaceae (2). It was observed one species of each one of the other families.

Keywords: Phytosociological characterization; Species occurrence; Araucaria forest.

\section{INTRODUÇÃO}

A Floresta Ombrófila Mista ou Floresta com Araucárias caracteriza-se pela presença da Araucaria angustifolia (Benth.), O. Ktze. como componente arbóreo principal de seu estrato, acompanhada por Bracatinga (Mimosa scabrella Benth.) e Erva mate (Ilex paraguariensis A. St.-Hil.) espécies atualmente exploradas e com significativo valor econômico em suas áreas de distribuição, com remanescentes dispersos nos estados do Rio Grande do Sul, Santa Catarina, Paraná e São Paulo.

De 1912 a 1992 o estado do Paraná sofreu uma intensa retirada de sua cobertura florestal, que foi substituída por atividades agrosilvipastoris, ou pela infra-estrutura econômica (principalmente estradas e hidrelétricas) e urbana. Nesse processo de desmatamento, a exploração madeireira também foi muito significativa. Após todo esse processo, em 1992 restavam, no estado, apenas 988.482 ha de florestas nativas, representando 4,99\% de seu território (LOPES, 2002).

As formas de exploração e métodos de manejo adotados podem alterar o ecossistema, modificando suas características a ponto de causar danos irreparáveis ao meio e à dinâmica do ambiente, podendo extinguir componentes importantes da estrutura florestal. Para que se possa explorar os recursos de maneira sustentável, faz-se necessário o pleno conhecimento da floresta e de seus estágios sucessionais, por meio da análise fitossociológica e do estudo da regeneração, gerando informações que possibilitem a aplicação correta de métodos e técnicas de interferência.

Desta forma, o estudo da vegetação é importante não só para a Taxonomia Vegetal e Fitogeografia, mas também no âmbito de pesquisa aplicada e de gestão, principalmente, com subsídios à silvicultura, manejo de bacias hidrográficas, manejo de fauna, preservação de táxons, conservação do ambiente e interpretação do potencial da terra para uso agropecuário (LONGHI, 1997). A classificação da vegetação deve ser sustentada não somente em critérios florísticos e ecológicos, mas também em observações realizadas sobre a característica fisionômica de elementos locais que possibilitem distinguir as diferentes tipologias vegetais com facilidade.

Segundo Longhi et al. (2000) para a caracterização da vegetação arbórea de uma determinada área, é necessário reconhecer as espécies presentes no local e fazer uma avaliação da estrutura horizontal e vertical da floresta, com o objetivo de verificar seu desenvolvimento. A estrutura horizontal permite a determinação da densidade, dominância, freqüência e importância das espécies na floresta e a estrutura vertical analisa o estágio de desenvolvimento desta floresta, com base na distribuição das espécies nos diferentes estratos.

Diversos autores concordam quanto a falta de pesquisas que retratem a estrutura nos distintos tipos florestais como Oliveira e Rotta (1983), Felfili et al. (2001a, 2001b); e Silva Junior et al. (2001) e Watzlawick et al. (2005). Para Klein (1960) as pesquisas conduzidas para estudos fitossociológicos nos locais de ocorrência da Araucária são insuficientes, estando esta afirmação embasada nas acentuadas variações fitofisionômicas, estruturais e florísticas desta formação florestal.

Levando em consideração as informações acima apresentadas, este estudo teve como objetivo conhecer, analisar e descrever a composição florística e a estrutura horizontal do componente arbóreo de um fragmento de Floresta Ombrófila Mista Montana, localizada em Clevelândia - PR. 


\section{MATERIAIS E MÉTODOS}

O presente estudo foi realizado em um fragmento de Floresta Ombrófila Mista Montana, com cerca de 240 ha, localizada no município de Clevelândia, região Sudoeste do Estado do Paraná, no terceiro planalto paranaense (Figura 1), a uma altitude média de 913 m.a.n.m., entre as coordenadas geográficas: $26^{\circ} 19^{\prime} 54^{\prime \prime}$ de Latitude Sul e 52 $13^{\prime} 39^{\prime \prime}$ de Longitude Oeste de Greenwich.

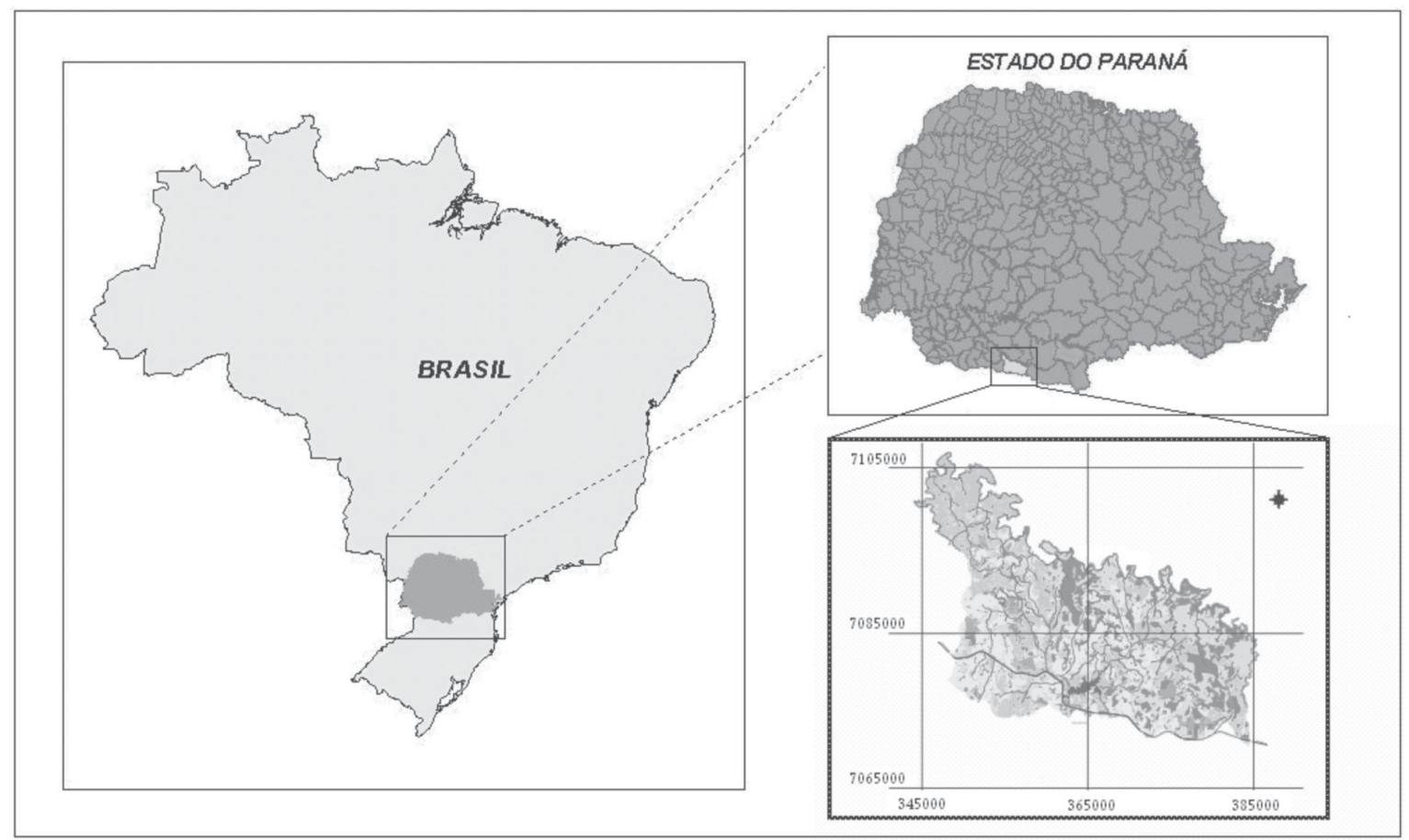

FIGURA 1 - Localização geográfica do município de Clevelândia, PR Figure 1 - Geographic localization of the municipality of Clevelandia, PR

O clima é temperado, possuindo todas as estações do ano bem definidas. Segundo a classificação climática de Wladimir Köeppen - Cfb, ou seja, clima subtropical úmido mesotérmico, de verões frescos, invernos com ocorrências de geadas severas e freqüentes, não apresentando estação seca. A média das temperaturas dos meses mais quentes não ultrapassa $22{ }^{\circ} \mathrm{C}$ e dos meses mais frios é inferior a $18{ }^{\circ} \mathrm{C}$, geralmente com umidade relativa do ar média acentuada de $78,9 \%$, e moderado índice pluviométrico, com precipitação média anual de $2.209 \mathrm{~mm}$.

O solo varia entre Litólico álico e Cambissolo álico, com afloramentos rochosos e muito suscetíveis à erosão. Nas partes mais baixas encontram-se os solos mais profundos, devido à declividade do terreno e conseqüente acúmulo de matéria orgânica. Como característica comum do Terceiro Planalto, a formação geológica basáltica da origem aos solos de rochas vulcânicas e aos solos argilosos de rochas sedimentares. A área em geral apresenta uma topografia de suavemente ondulada a ondulada, com $63 \%$ entre declividade de 0 a 15 graus, $43 \%$ de 16 e 25 graus e o restante da área com declividade superior a 26 graus.

Para o estudo da vegetação, utilizou-se o método de área fixa, sendo instaladas 20 unidades amostrais de $20 \times 20 \mathrm{~m}(400 \mathrm{~m} 2)$ de forma aleatória, totalizando uma amostragem de $8.000 \mathrm{~m} 2$, onde todos os indivíduos arbóreos e arbustivos com DAP ? $20 \mathrm{~cm}$ foram medidos e identificados.

De posse dos dados, as espécies foram classificadas e tiveram seus parâmetros fitossociológicos estimados para a descrição da estrutura horizontal e vertical da comunidade, os quais encontram-se definidos nos trabalhos de Kent e Coker (1992) e Lamprecht (1964). 


\section{RESULTADOS E DISCUSSÕES}

A Figura 2 apresenta o acréscimo de espécies arbóreas com DAP ? $20 \mathrm{~cm}$ em relação à área de amostragem. Nota-se que a partir de $4.400 \mathrm{~m} 2$ de área amostral, ou seja, após a unidade amostral 11, ocorre a estabilização da curva. Isto indica que as 20 unidades utilizadas foram suficientes para caracterizar a vegetação em estudo e em termos de composição de espécies arbóreas. Em estudos realizados em Floresta Ombrófila Mista por Watzlawick et al. (2002) e Durigan (1999) também foi verificada a estabilização da curva acima dos $4.000 \mathrm{~m} 2$ de área amostral.

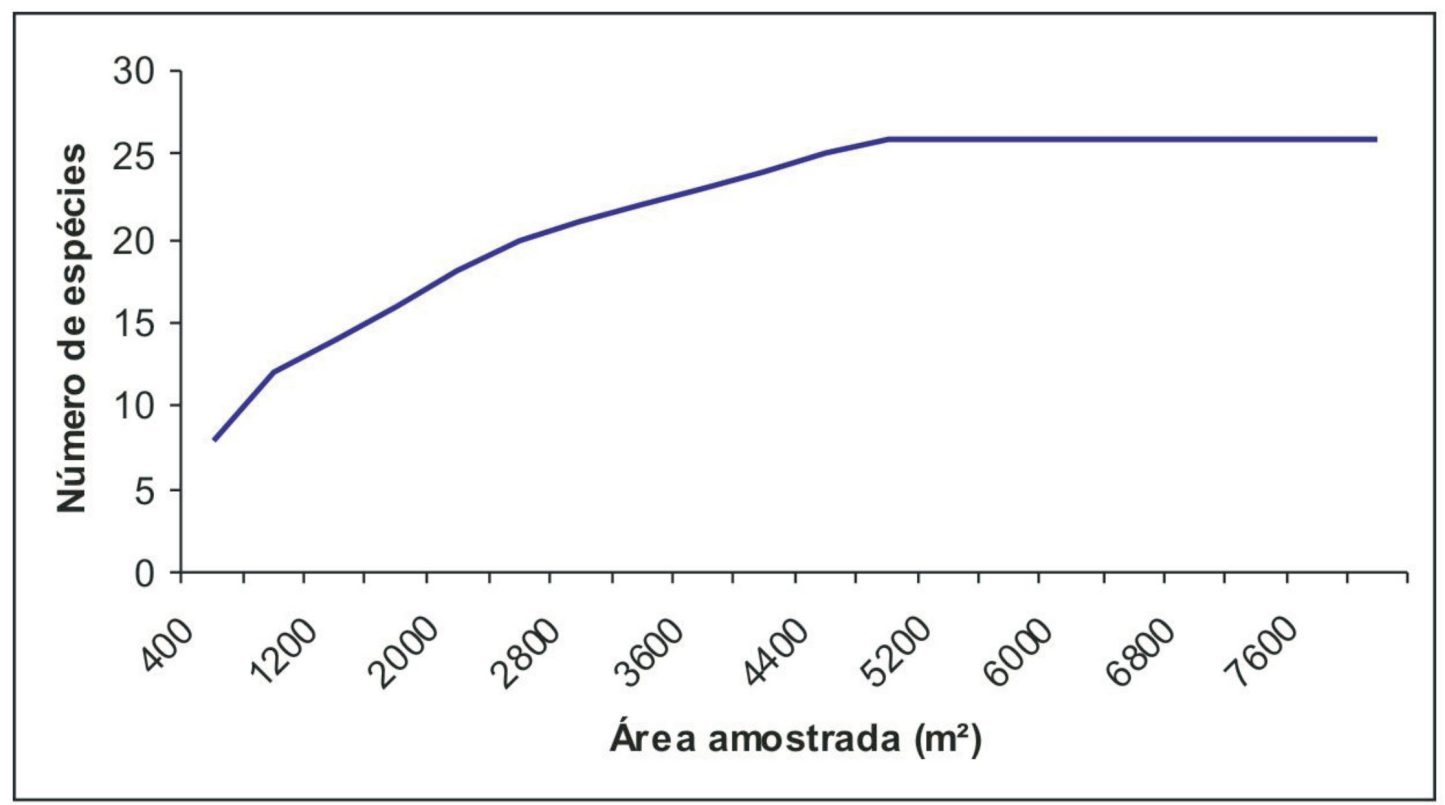

FIGURA 2 - Relação do número de espécies com tamanho da área amostral em um fragmento de Floresta Ombrófila Mista, em Clevelândia, PR

Figure 2 - Relationship between the number of species and size of sampling units in a Subtropical Ombrophilous Forest fragment, in Clevelandia, PR

$\mathrm{Na}$ Tabela 1 estão relacionadas às espécies em ordem alfabética de famílias e gêneros, bem como os respectivos nomes vulgares. Foram inventariados 232 indivíduos, pertencentes a 26 espécies, 23 gêneros, distribuídos em 18 famílias botânicas. Pessoa (1994) em análise semelhante, no município de Santa Tereza do Oeste - PR, encontrou 27 espécies, sendo este um número aproximado ao descrito neste estudo. Em observações feitas em outras regiões do Estado do Paraná por Longhi (1980), Takeda (1998) e Nectandra (1992) para a mesma tipologia florestal com indivíduos de DAP $\geq 20 \mathrm{~cm}$, foram encontrados maior número de espécies, gêneros e famílias botânicas.

Constatou-se que a floresta apresentou diversidade mediana onde o Índice de ShannonWeaver estimado foi 2,74 , indicando uma distribuição uniforme do número de indivíduos em relação ao número de espécies. Para Brower e Zar (1984) a diversidade da vegetação pode ser observada por vários índices, sendo que o de Shannon é o mais utilizado para expressar as características da comunidade pelo seu nível de organização biológica. 
Análise florística e estrutural do componente arbóreo de um fragmento de Floresta Ombrófila Mista em Clevelândia, sudoeste do Paraná

TABELA 1 - Relação das espécies arbóreas amostradas em um fragmento de Floresta Ombrófila Mista, localizado em Clevelândia, PR

Table 1 - Tree species identified in a Subtropical Ombrophilous Forest fragment, located in Clevelandia, PR

FAMILIA / NOME CIENTÍFICO

ANACARDIACEAE

Lithraea brasiliensis Marchand

AQUIFOLIACEAE

Ilex paraguariensis A. St.-Hil.

AQUIFOLIACEAE

Ilex theezans Mart.

ARAUCARIACEAE

Araucaria angustifolia (Bertol.) O. Kuntze

ASTERACEAE

Piptocarpha angustifolia Dusén

CANELLACEAE

Capsicodendron dinisii (Schwacke) Occhioni

CLETHRACEAE

Clethra scabra Persoon

CUNONIACEAE

Lamanonia ternata Vell.

EUPHORBIACEAE

Sapium glandulatum (Vell.) Pax

EUPHORBIACEAE

Sebastiania commersoniana (Baill.) L.B. Sm. \& Downs

FABACEAE

Machaerium stipitatum (DC.) Vogel

FLACOURTIACEAE

Casearia decandra Jacq.

LAURACEAE

Ocotea odorifera (Vell.) Rohwer

LAURACEAE

Ocotea porosa (Nees \& Mart.) Barroso

LAURACEAE

Ocotea puberula (Rich.) Nees

MELIACEAE

Cedrela fissilis Vell.

MYRSINACEAE

Myrsine ferruginea (Ruiz \& Pav.) Spreng.

MYRTACEAE

Campomanesia xanthocarpa O. Berg.

MYRTACEAE

Myrcengenia euosma (O. Berg) D. Legrand

PODOCARPACEAE

Podocarpus lambertii Klotzsch ex Eichler

ROSACEAE

Prunus sellowii Koehne

SAPINDACEAE

Allophylus edulis (A. St.-Hil., Cambess. \& A. Juss.) Radlk.

SAPINDACEAE

Cupania vernalis Cambess.

SAPINDACEAE

Diatenopteryx sorbifolia Radlk.

SAPINDACEAE

Matayba elaeagnoides Radlk.

TILIACEAE

Luebea divaricata Mart.
NOME POPULAR

Bugreiro

Erva - mate

Orelha-de-mico

Araucaria

Vassorão branco

Pimenteira

Cajuja

Guaraperê

Leiteiro

Branquilho

Sapuva

Guaçatunga

Canela sassafrás

Imbúia

Canela-guaicá

Cedro

Capororoca

Guavirova

Guamirim branco

Pinheiro bravo

Pessegueiro bravo

Vacum

Camboatã

Maria preta

Miguel Pintado

Açoita cavalo

Rev. Acad., Ciênc. Agrár. Ambient., Curitiba, v. 6, n. 2, p. 239-248, abr./jun. 2008 
As famílias que apresentaram maior número de indivíduos são apresentadas na Figura 3, sendo que as que mais se destacaram em riqueza de espécie foram: Sapindaceae (4); Lauraceae (3); Myrtaceae, Euphorbiaceae e Aquifoliaceae (2). As demais famílias apresentaram apenas uma espécie. Resultados de estudos realizados por Koehler; Péllico Netto; Sanquetta (1998), Negrelle e Silva (1992) e Watzlawick et al. (2005) apresentaram números superiores de riqueza de espécie por família.

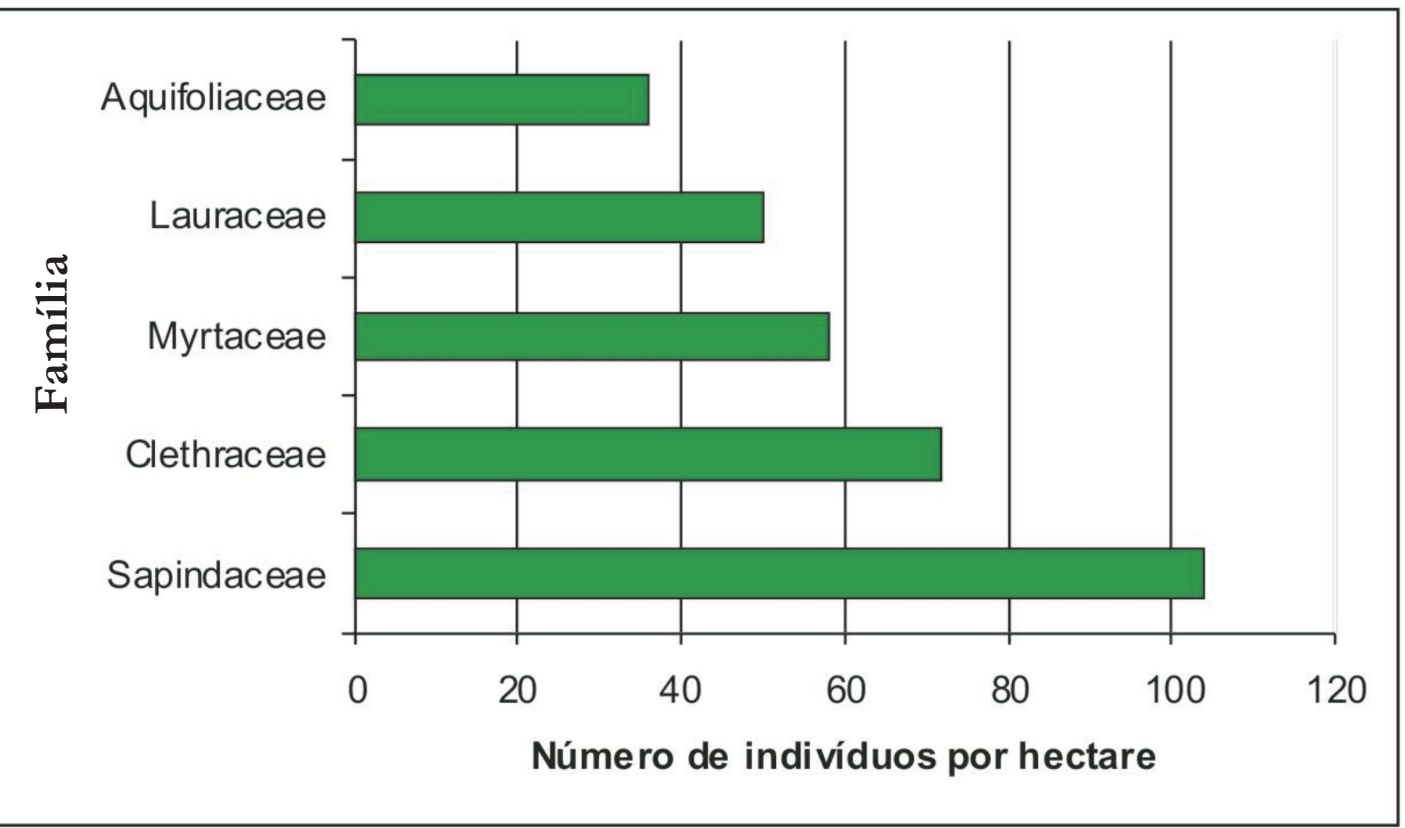

FIGURA 3 - Número de indivíduos encontrados por hectare das cinco famílias de maior freqüência

Figure 3 - Number of observed individuals per hectare of the five most frequent families

Nenhuma das espécies identificadas esteve presente em todas as unidades amostrais, sendo que as de maior freqüência foram: Cupania vernalis (15), Araucaria angustifolia (12), Lamanonia ternata (11) e Myrceugenia euosma (8). Tais espécies contribuíram com 36,72\% da frequência relativa total. Os resultados dos parâmetros fitossociológicos constam na Tabela $2 \mathrm{em}$ ordem de valor de importância (VI) das espécies. 
Análise florística e estrutural do componente arbóreo de um fragmento de Floresta Ombrófila Mista em Clevelândia, sudoeste do Paraná

TABELA 2 - Lista das espécies arbóreas encontradas em um fragmento de Floresta Ombrófila Mista Montana, em Clevelândia, PR, com seus respectivos parâmetros estruturais

Table 2 - List of observed tree species in a Subtropical Ombrophilous Montane Forest fragment, in Clevelandia, $P R$, with their structural parameters

\begin{tabular}{|c|c|c|c|c|c|c|c|}
\hline ESPÉCIE & $\begin{array}{c}\text { DA } \\
\text { Ind/ha }\end{array}$ & $\begin{array}{l}\text { D Abs } \\
\mathrm{m}^{2} / \mathrm{ha}\end{array}$ & $\begin{array}{c}\text { AB Rel } \\
\%\end{array}$ & $\begin{array}{l}\text { D Rel } \\
\%\end{array}$ & $\begin{array}{l}\text { FR } \\
\%\end{array}$ & $\begin{array}{c}\text { IVC } \\
\%\end{array}$ & $\begin{array}{c}\text { IVI } \\
\%\end{array}$ \\
\hline Cupania vernalis & 48,75 & 4,61 & 16,81 & 15,53 & 11,72 & 16,17 & 14,69 \\
\hline Lamanonia ternata & 40,00 & 5,15 & 13,79 & 17,35 & 8,59 & 15,57 & 13,25 \\
\hline Araucaria angustifolia & 16,25 & 3,29 & 5,60 & 11,09 & 9,38 & 8,35 & 8,69 \\
\hline Myrceugenia euosma & 32,50 & 1,66 & 11,21 & 5,58 & 7,03 & 8,39 & 7,94 \\
\hline Ilex paraguariensis & 21,25 & 1,43 & 7,33 & 4,83 & 6,25 & 6,08 & 6,14 \\
\hline Podocarpus lambertii & 16,25 & 1,51 & 5,60 & 5,08 & 5,47 & 5,34 & 5,38 \\
\hline Ocotea porosa & 12,50 & 1,50 & 5,69 & 4,95 & 4,86 & 4,67 & 4,73 \\
\hline Casearia decandra & 13,75 & 0,99 & 4,74 & 3,35 & 5,47 & 4,04 & 4,52 \\
\hline Piptocarpha angustifolia & 12,50 & 1,21 & 4,31 & 4,07 & 4,69 & 4,19 & 4,35 \\
\hline Ocotea puberula & 8,75 & 1,36 & 3,02 & 4,59 & 3,91 & 3,81 & 3,84 \\
\hline Ocotea odorífera & 10,00 & 1,10 & 2,07 & 3,81 & 3,74 & 3,59 & 3,64 \\
\hline Matayba elaeagnoides & 8,75 & 1,09 & 3,02 & 3,69 & 3,91 & 3,35 & 3,54 \\
\hline Cedrela fissilis & 6,25 & 1,06 & 2,16 & 3,58 & 3,13 & 2,87 & 2,95 \\
\hline Lithraea brasiliensis & 7,50 & 0,67 & 2,59 & 2,26 & 3,91 & 2,42 & 2,92 \\
\hline Prunus sellowii & 7,50 & 0,66 & 2,59 & 2,24 & 3,91 & 2,41 & 2,91 \\
\hline Clethra scabra & 5,00 & 0,40 & 1,72 & 1,34 & 2,34 & 1,53 & 1,80 \\
\hline Allophylus edulis & 5,00 & 0,29 & 1,72 & 0,98 & 2,34 & 1,35 & 1,68 \\
\hline Diatenopteryx sorbifolia & 2,50 & 0,50 & 0,86 & 1,70 & 1,56 & 1,28 & 1,37 \\
\hline Sebastiania commersoniana & 3,75 & 0,24 & 1,29 & 0,82 & 1,56 & 1,05 & 1,22 \\
\hline Campomanesia xanthocarpa & 3,75 & 0,14 & 1,29 & 0,47 & 1,56 & 0,88 & 1,11 \\
\hline Capsicodendron dinisii & 1,25 & 0,21 & 0,43 & 0,72 & 0,78 & 0,58 & 0,65 \\
\hline Luehea divaricata & 1,25 & 0,18 & 0,43 & 0,61 & 0,78 & 0,52 & 0,61 \\
\hline Ilex theezans & 1,25 & 0,12 & 0,43 & 0,42 & 0,78 & 0,43 & 0,54 \\
\hline Machaerium stipitatum & 1,25 & 0,12 & 0,43 & 0,40 & 0,78 & 0,41 & 0,54 \\
\hline Sapium glandulatum & 1,25 & 0,11 & 0,43 & 0,37 & 0,78 & 0,40 & 0,53 \\
\hline Myrsine ferruginea & 1,25 & 0,06 & 0,43 & 0,19 & 0,78 & 0,31 & 0,47 \\
\hline Total & 290 & 29,67 & 100 & 100 & 100 & 100 & 100 \\
\hline
\end{tabular}

$\mathrm{DA}=$ Densidade absoluta (indivíduos $/ \mathrm{ha}) ; \mathrm{D}$ Abs = Área basal absoluta $(\mathrm{m} 2 / \mathrm{ha}) ; \mathrm{AB}$ Rel = Área basal relativa $(\%)$; Rel = Densidade relativa (\%); FR = Freqüência relativa (\%); IVI = Índice de Valor de importância (0-100); IVC = Índice de Valor de Cobertura (0-100).

A abundância total de 290 indivíduos/ha estimada para a comunidade arbórea foi baixa, quando comparada com o resultado de outros autores, obtidos na Floresta Ombrófila Mista em estágios distintos de desenvolvimento (DIAS et al., 1998; NASCIMENTO; LONGHI; BRENA, 2001). Isto pode ser explicado pelo estágio de sucessão avançado da área e a escolha do DAP mínimo ser maior ou igual a $20 \mathrm{~cm}$, o que acarreta menor inclusão de indivíduos.

As espécies mais abundantes e que merecem destaque, quanto ao maior número de indivíduos por hectare amostrados, foram respectivamente: Cupania vernalis (48,75), Lamanonia ternata $(40,00)$, Myrceugenia euosma (32,50), Ilex paraguariensis $(21,25)$, Podocarpus lambertii e Araucaria angustifolia $(16,25)$. Tais espécies contribuíram com $60,34 \%$ do número total de árvores mensuradas, sendo que a Cupania vernalis participou com 11,72\%. Em uma floresta com Araucaria em Caçador - SC, Negrelle e Silva (1992) obtiveram valores inferiores, onde a Cupania vernalis participou com $8,82 \%$ do número total de árvores amostradas, porém com indivíduos de DAP acima de $5 \mathrm{~cm}$. Para a mesma espécie e diâmetro mínimo, na Floresta Ombrófila Mista Montana em Criúva - RG, Rondon Neto et al. (2002) obtiveram valor inferior, onde esta participa com 1,27\% do número total de indivíduos. 
A floresta apresentou uma distribuição diamétrica regular. Para Longhi (1980) este tipo de distribuição permite que o processo dinâmico da floresta se perpetue, pois a ausência súbita de indivíduos dominantes dará lugar a árvores de reposição. O DAP médio da comunidade arbórea foi estimado em $34,1 \mathrm{~cm}$, sendo que cerca de $75,23 \%$ do total de indivíduos amostrados possuem DAP maior que $20 \mathrm{~cm}$ e menor que $40 \mathrm{~cm}$; destes $45,23 \%$ possuem DAP maior que $20 \mathrm{~cm}$ e menor que 30 , e 30\% apresentam DAP entre 30 e $39 \mathrm{~cm}$, conforme pode-se observar na Figura 4.

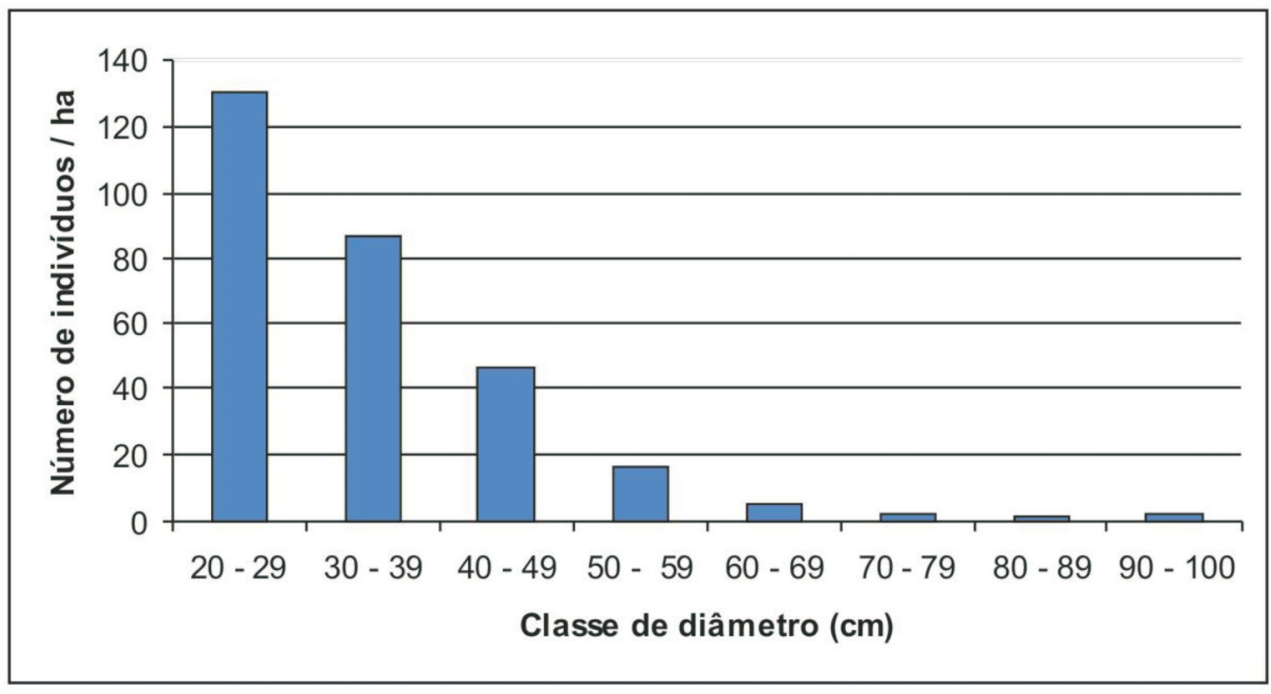

FIGURA 4 - Distribuição diamétrica porclasse de diâmetro dosindivíduos arbóreos, amostrados em um fragmento de Floresta Ombrófila Mista, em Clevelândia, PR

Figure 4 - Diametric distribution of trees by diameter class, sampled in a Subtropical Ombrophilous Forest fragment, in Clevelandia, PR

Na Figura 5 pode ser observado as dez espécies que apresentaram os maiores Valores de Importância e juntas contribuíram com $73,3 \%$ do VI total. A dominância e a área basal foram os parâmetros que contribuíram para que Cupania vernalis e Lamanonia ternata fossem as espécies de maior valor de importância e representassem juntas $27,94 \%$ do VI total.

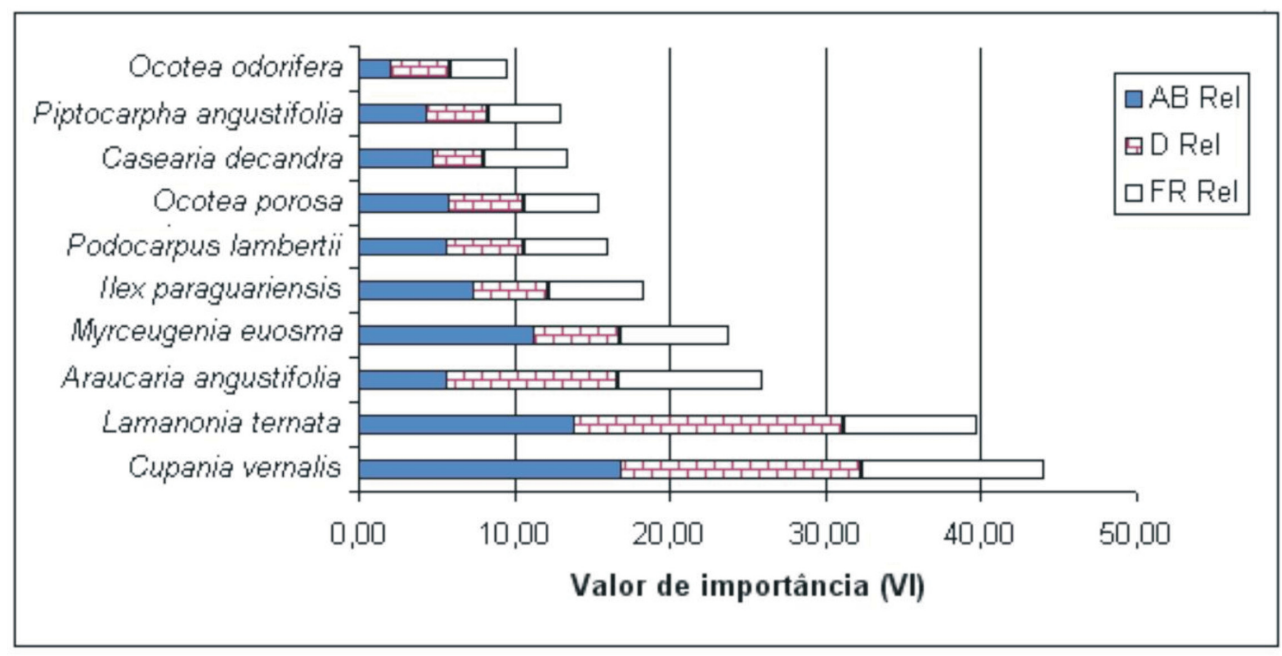

FIGURA 5 - Distribuição do VI das 10 principais espécies arbóreas de um fragmento de Floresta Ombrófila Mista, em Clevelândia, PR

Figure 5 - Distribution of VI of the 10 most important species of a Subtropical Ombrophilous Forest fragment, in Clevelandia, PR 


\section{CONCLUSÕES}

Por meio da análise dos resultados obtidos neste estudo pode-se concluir que:

- a área de estudo apresentou uma baixa diversidade florística, se comparado com outros estudos realizados para a mesma tipologia florestal;

- as famílias Sapindaceae, Lauraceae, Myrtaceae, Euphorbiaceae e Aquifoliaceae apresentaram maior variedade de espécies, indicando características específicas adequadas para desenvolvimento em área alterada;

- as espécies Cupania vernalis, Lamanonia ternata, Araucaria angustifolia, Myrceugenia euosma e Ilex paraguariensis foram as mais características da comunidade analisada, representando $50,7 \%$ do valor de importância total das espécies;

- a inexistência de estudos florísticos e estruturais da vegetação na região sudoeste do estado do Paraná inviabiliza comparações com componentes florestais na mesma região do Estado.

\section{REFERÊNCIAS}

BROWER, J. E.; ZAR, J. H. Field and laboratory methods for general. 2nd ed. Iowa: Brown Publishers, 1984.

DIAS, M. C. et al. Composição florística e fitossociológica do componente arbóreo das florestas ciliares do rio Iapó, na bacia do rio Tibagi, Tibagi-PR. Revista Brasileira de Botânica, São Paulo, v. 21, n. 2, p. 183-195, 1998.

DURIGAN, M. E. Florística, dinâmica e análise protéica de uma Floresta Ombrófila Mista em São João do Triunfo - PR. 1999. 125 f. Dissertação (Mestrado em Engenharia Florestal) Universidade Federal do Paraná, Curitiba, 1999.

FELFILI, J. M. et al. Flora fanerogâmica das matas de galeria e ciliares do Brasil Central. In: RIBEIRO, J. F.; FONSECA, C. E. L.; SOUZA-SILVA, J. C. Cerrado: caracterização e recuperação de matas de galeria. Planaltina, DF: [s. n.], 2001a. v. 1. p. 195-209.

O projeto biogeografia do bioma cerrado: hipóteses e padronização da metodologia. In: GARAY, I.; DIAS, B. Conservação da biodiversidade em ecossistemas tropicais. Petrópolis, RJ: [s. n.], 2001b. p. 157-173.

KENT, M.; COKER, P. Vegetation description and analysis: a practical approach. London: Blackwell, 1992.

KLEIN, R. M. O aspecto dinâmico do pinheiro brasileiro. Sellowia, Itajaí, v. 12, n. 12, p. 17-44, 1960.

KOEHLER, A.; PÉLLICO NETTO, S.; SANQUETTA, C. R. Análise da estrutura de uma Floresta Ombrófila Mista semidevastada, Fazenda Gralha Azul, Região Metropolitana de Curitiba, com implicações ao manejo. Revista Acadêmica: Ciências Agrárias e Ambientais, Curitiba, v. 9, n. 1, p. 37-60, 1998.

LAMPRECHT, H. Ensayo sobre la estrutura floristica de la parte sur - oriental del bosque universitario "El Caimital", Estado Barinas. Mérida, Revista Forestal Venezolana, v. 7, n. 10/11, p. 77-119, 1964.

LONGHI, S. J. A estrutura de uma floresta natural de Araucaria angustifolia (Bert.) O. Ktze., no sul do Brasil. 1980. 198 f. Dissertação (Dissertação de Mestrado em Engenharia Florestal) Universidade Federal do Paraná, Curitiba, 1980. 
LONGHI, S. J. Agrupamento e análise fitossociológica de comunidades florestais na subbacia hidrográfica do Rio Passo Fundo-RS. 1997. 193 f. Tese (Doutorado em Ciências Florestais) - Universidade Federal do Paraná, Curitiba, 1997.

LONGHI, S. J. et al. Aspectos fitossociológicos de fragmento de floresta estacional decidual, Santa Maria, RS. Ciência Florestal, Santa Maria, v. 10, n. 2, p. 59-74, 2000.

PESSOA SUL FLORESTAL S/C LTDA. Estudos e relatório de impacto ambiental: projeto agrícola fazenda Andrada - lote 25-C, Santa Tereza do Oeste - PR. Curitiba: [s.n.], 1994. v. I/II.

LOPES, I. V. et. al. Gestão ambiental no Brasil: experiência e sucesso. 5. ed. Rio de Janeiro: FGU, 2002.

NASCIMENTO, A. R. T.; LONGHI, S. J.; BRENA, D. A. Estrutura e padrões de distribuição espacial de espécies arbóreas em uma amostra de Floresta Ombrófila Mista em Nova Prata - RS. Ciência Florestal, Santa Maria, v. 11, n. 1, p. 105-119, 2001.

NECTANDRA - AEROFOTOGRAMETRIA E ENGENHARIA S/A. Estudo de impacto ambiental - relatório de impacto ambiental: plano de manejo florestal da fazenda Palmital. Curitiba: [n.s.], 1992.

NEGRELLE, R. A. B.; SILVA, F. C. da. Fitossociologia de um trecho de floresta com Araucaria angustifolia (Bert.) O. Ktze., no município de Caçador - SC. Bol. Pesq. Florestal, Colombo, n. 24/ 25, p. 37-54, 1992.

OLIVEIRA, Y. M. M. de; ROTTA, E. Levantamento da estrutura vertical de uma Mata de Araucária do primeiro planalto paranaense. In: ALVARENGA, R. de M. (Coord.). CONGRESSO FLORESTAL BRASILEIRO, 4., 1983, Belo Horizonte. Anais... Jaguaré: SBS, 1983. p. 106-111.

RONDON NETO, R. M. et al. Análise florística e estrutural de um fragmento de Floresta Ombrófila Mista Montana, situada em Criúva, RS - Brasil. Ciência Florestal, Santa Maria, v. 12, n. 1, p. 29-37, 2002.

SILVA JÚNIOR, M. C. et al. Análise da flora arbórea de matas de galeria no Distrito Federal: 21 levantamentos. In: RIBEIRO, J. F.; FONSECA, C. E. L.; SOUSA-SILVA, J. C. Cerrado: caracterização e recuperação de Matas de Galeria. Planaltina: Embrapa Cerrados, 2001. p. 142-191.

TAKEDA, I. J. M. et al. Estrato arbóreo de Floresta Ombrófila Mista ciliar da Fazenda Trevo, município de Jaguariaíva, PR. In: CONGRESSO NACIONAL DE BOTÂNICA, 49., 1998. Salvador. Resumos... Salvador: SBB, 1998. p. 399.

WATZLAWICK, L. F. et al. Caracterização da composição florística e estrutura de uma Floresta Ombrófila Mista no município de General Carneiro - PR. Revista Ambiência, Guarapuava, v. 1, n. 2, p. 229-237, 2005.

WATZLAWICK, L. F. et al. Aspectos florístico e estrutural de um fragmento de floresta com Araucária utilizado para o pastoreio de bovinos. Ciência \& Natura, Santa Maria, v. 24, p. 77-90, 2002.

Recebido: 12/10/2007

Received: 10/12/2007

Aprovado: 15/01/2008

Approved: 01/15/2008 